\title{
Differences and overlap in self-reported symptoms of bipolar
} disorder and borderline personality disorder

\section{Baryshnikov, I.}

2015-11

Baryshnikov , I, Aaltonen , K, Koivisto , M , Naatanen , P , Karpov , B , Melartin , T , Heikkinen, M , Ketokivi , M , Joffe , G \& Isometsa , E 2015, ' Differences and overlap in self-reported symptoms of bipolar disorder and borderline personality disorder ' , European Psychiatry , vol. 30 , no. 8 , pp. 914-919 . https://doi.org/10.1016/j.eurpsy.2015.08.002

http://hdl.handle.net/10138/223835

https://doi.org/10.1016/j.eurpsy.2015.08.002

publishedVersion

Downloaded from Helda, University of Helsinki institutional repository.

This is an electronic reprint of the original article.

This reprint may differ from the original in pagination and typographic detail.

Please cite the original version. 


\title{
Original article
}

\section{Differences and overlap in self-reported symptoms of bipolar disorder and borderline personality disorder}

\author{
I. Baryshnikov ${ }^{\mathrm{a}, 1}$, K. Aaltonen ${ }^{\mathrm{a}, \mathrm{b}, \mathrm{d}, 1}$, M. Koivisto ${ }^{\mathrm{a}, 1}$, P. Näätänen ${ }^{\mathrm{a}, 1}$, B. Karpov ${ }^{\mathrm{a}, 1}$,

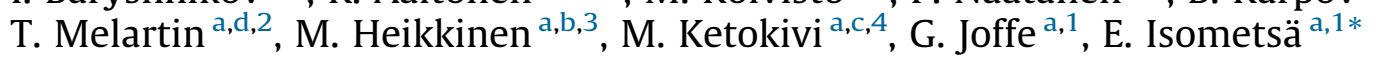 \\ ${ }^{a}$ Department of Psychiatry, University of Helsinki and Helsinki University Hospital, PO Box 22, Välskärinkatu 12 A, 00014 Helsinki, Finland \\ ${ }^{\mathrm{b}}$ Department of Social Services and Health Care, Helsinki, Finland \\ c Operations and Technology Department, IE Business School - IE University, Madrid, Spain \\ d Department of Psychiatry, Helsinki University Central Hospital, PO Box 590, 00029 HUS, Helsinki, Finland
}

\section{A R T I C L E I N F O}

\section{Article history:}

Received 8 June 2015

Received in revised form 4 August 2015

Accepted 9 August 2015

Available online 6 October 2015

\section{Keywords:}

Borderline personality disorder

Bipolar disorder

McLean Screening Instrument

Mood Disorder Questionnaire

\begin{abstract}
A B S T R A C T
Background: Differential diagnosis between bipolar disorder (BD) and borderline personality disorder (BPD) is often challenging due to some overlap in symptoms and comorbidity of disorders. We investigated correlations in self-reported symptoms of BD and BPD in screening questionnaires at the levels of both total scores and individual items and explored overlapping dimensions.

Methods: The McLean Screening Instrument (MSI) for BPD and the Mood Disorder Questionnaire (MDQ) for BD were filled in by patients with unipolar and bipolar mood disorders $(n=313)$ from specialized psychiatric care within a pilot study of the Helsinki University Psychiatric Consortium. Pearson's correlation coefficients between total scores and individual items of the MSI and the MDQ were estimated. Relationships between MDQ and MSI were evaluated by exploratory factor analysis (EFA). Results: The correlation between total scores of the MDQ and MSI was moderate $(r=0.431, P<0.001)$. Significant correlations were found between the MSI items of "impulsivity" and "mood instability" and all MDQ items $(P<0.01)$. In the EFA, the MSI "impulsivity" and "mood instability" items had significant crossloadings ( 0.348 and 0.298 , respectively) with the MDQ factor. The MDQ items of "irritability", "flight of thoughts" and "distractibility" $(0.280,0.210$ and 0.386 , respectively) cross-loaded on the MSI factor. Conclusions: The MDQ and MSI items of "affective instability", "impulsivity", "irritability", "flight of thoughts" and "distractibility" appear to overlap in content. The other scale items are more disorderspecific, and thus, may help to distinguish BD and BPD.
\end{abstract}

(c) 2015 Elsevier Masson SAS. All rights reserved.

\section{Introduction}

Borderline personality disorder (BPD) is often comorbid with mood disorders and shares some phenomenological features with them, particularly with bipolar disorder (BD) [3]. This has resulted in numerous discussions about relationship of the BPD with BD, some authors even suggesting than BPD should be considered as a part of the bipolar spectrum disorders [1], others emphasizing differences between them [24]. Some recent studies have indicated partial overlap in pathogenetic mechanisms and genetics of the disorders, although clear distinctions have also been found

\footnotetext{
* Corresponding author. Tel.: +358 9 4711; fax: +3589 47163735.

E-mail address: erkki.isometsa@hus.fi (E. Isometsä).

1 Tel.: +358 94711

2 Tel.: +358 9 4711; fax: +358947163735

3 Tel.: +3589 4711; fax: +358947175455.

4 Tel.: +358 401731112 .
}

$[6,31,32,34]$. Phenomenological and neurobiological overlap may underlie common difficulties in differential diagnosis between BPD and BD. However, because of notable differences in their treatment [24], it is important to distinguish the two disorders in psychiatric and other clinical settings.

Numerous previous studies have found BD to be widely underrecognized $[11,17,25]$, or recognized only after a long delay [17]. The same may be also true for BPD [19]. However, as BD has received increasing clinical recognition and attention in recent years, some reports have implied that $\mathrm{BD}$ also may also become overdiagnosed at times and, moreover, patients misdiagnosed with BD may be significantly more likely to be later diagnosed with BPD [38-40]. There is a possibility of overdiagnosis of BPD, too.

In the absence of widely approved biomarkers specific for each disorder, the diagnoses of BD and BPD remain clinical [18]. The systematic use of screening tests and structured clinical interviews may considerably improve detection of disorders in clinical psychiatry [29]. The McLean Screening Instrument (MSI) for BPDs 
and the Mood Disorder Questionnaire (MDQ) for BD are useful and valid screening instruments used in psychiatric settings to improve recognition of these disorders. Both are based on self-reported symptoms $[11,12,36]$.

In this study, we aimed to investigate the correlation between the MSI and the MDQ at the levels of both total scores and individual items, and explore overlapping and non-overlapping self-reported items of BD and BPD.

\section{Methods}

\subsection{The Helsinki University Psychiatric Consortium (HUPC)}

This investigation is a part of the Helsinki University Psychiatric Consortium (HUPC) pilot study, a collaborative research project between the faculty of medicine of the university of Helsinki; the department of mental health and substance abuse services of the National institute for health and welfare; the Department of social services and health care, city of Helsinki; and the department of psychiatry, university of Helsinki and Helsinki university hospital. The study protocol was approved by the Ethics committee of Helsinki university central hospital.

\subsection{Setting}

The study was conducted in 10 community mental health centres, three psychiatric inpatient units and one day-hospital offering specialized secondary public mental health services in the metropolitan area of Helsinki between 12.1.2011 and 20.12.2012.

\subsection{Sampling}

Inclusion criteria for participation in the pilot study were patients' age of over 18 years and provision of informed consent. Patients with mental retardation, neurodegenerative disorders and insufficient Finnish language skills were excluded. Stratified patient sampling selection was performed by identifying all patients within a certain day or week in a unit or by randomly drawing eligible patients from patient lists. Patients treated for psychotic disorders, neuropsychiatric disorders and substance use disorders were excluded from our study. Of the 902 eligible patients with mood, neurotic or personality disorders, 372 declined to participate and 216 were lost for other reasons.

\subsection{Clinical diagnoses}

The validity of the clinical diagnoses assigned by the attending physicians was critically evaluated by the authors (I.B., K.A., M.K., B.K.) by re-examining all available information from the patient records. Authors K.A., I.B. and B.K. were residents of psychiatry trained in diagnostic evaluations; in any unclear cases, the senior psychiatrists (M.K., E.I., G.J., M.H.) were consulted. The validated clinical diagnoses were based on the ICD-10-DCR [35]. Lifetime principal diagnosis was assigned. Although there is no division of BD into types I (BD-I) and II (BD-II) in the ICD-10, we subtyped patients into these categories according to the DSM-IV [2]. This distinction is established clinical practice in Finland and included in the national BD treatment guidelines.

\subsection{Description of patients}

Altogether 313 patients participated in the study. Their mean age was $41.7 \pm 13.1$ years, and 229 (73.1\%) were female. All patients were allocated into groups according to the lifetime principal diagnosis; (see Table 1). Patients comprised those with depressive episode (F32-F33; future unipolar depression [UD] [ $n=183$; mean age $41.4 \pm 13.3$ years]), bipolar affective disorder (F31; $[n=99$, mean age $43.7 \pm 12.7$ years $]$ ) and others $(n=31$, mean age $36.2 \pm 13$ years $)$. Among patients with BD, 36 (36.3\%) had type I, 55 (55.5\%) type II and 8 (8\%) unspecified type. Fifteen patients with neurotic and somatoform disorders, four patients with eating disorders, five patients with dysthymia and seven patients with BPD as lifetime principal diagnosis formed the group "others". There were 65 patients with BPD among all patients, including patients with BPD as lifetime principal diagnosis and as comorbid. Their mean age was $37.5 \pm 13$ years.

The analysis of representativeness was undertaken by comparing patients suffering from UD or BD in the HUPC with patients with the same diagnoses treated in 2011 and 2012 in psychiatric care organizations. No significant differences emerged in sex and age between these two groups (data not shown).

\subsection{Mood Disorder Questionnaire (MDQ)}

The MDQ is a brief self-report instrument for screening symptoms or behaviours related to a manic or hypomanic syndrome [12], and it has been translated into Finnish [13]. The first part of the MDQ includes 13 items requiring a "yes/no"

Table 1

Characteristics of MDQ and MSI responders $(n=313)$.

\begin{tabular}{|c|c|c|c|c|c|c|}
\hline & \multicolumn{2}{|l|}{$\mathrm{BD}$} & \multicolumn{2}{|l|}{ UD } & \multicolumn{2}{|l|}{ Others } \\
\hline & $n$ & $\%$ & $n$ & $\%$ & $n$ & $\%$ \\
\hline Number & 99 & 32 & 183 & 58 & 31 & 10 \\
\hline Age (mean) & $43.7 \pm 12.7$ & & $41.4 \pm 13.3$ & & $36.2 \pm 13$ & \\
\hline $\mathrm{BPD}$ & 17 & 17.2 & 39 & 21.3 & 9 & 29 \\
\hline Sex (male) & 36 & 36.3 & 42 & 22.9 & 6 & 19.4 \\
\hline \multicolumn{7}{|l|}{ Marital state } \\
\hline Married & 20 & 20.2 & 39 & 21.3 & 4 & 12.9 \\
\hline Cohabitation & 17 & 17.2 & 29 & 15.8 & 3 & 9.7 \\
\hline Unmarried & 32 & 32.2 & 75 & 41 & 17 & 55 \\
\hline Divorced & 29 & 29.3 & 35 & 19.1 & 6 & 19.4 \\
\hline Widowed & 1 & 1 & 3 & 1.7 & 0 & 0 \\
\hline \multicolumn{7}{|l|}{ Job } \\
\hline Retired due to mental disorder & 37 & 37.4 & 23 & 12.5 & 6 & 19.4 \\
\hline Unemployed & 10 & 10 & 18 & 9.8 & 8 & 26 \\
\hline Sick leave & 22 & 22.2 & 64 & 35 & 5 & 16.1 \\
\hline Retired due to another reason & 1 & 1 & 8 & 4.4 & 0 & 0 \\
\hline Student & 7 & 7.1 & 24 & 13.1 & 6 & 19.4 \\
\hline Employed & 20 & 20.2 & 30 & 16.4 & 5 & 16.1 \\
\hline Unemployed due to another reason & 2 & 2.2 & 14 & 7.7 & 1 & 3.2 \\
\hline
\end{tabular}

BD: bipolar disorder; UD: unipolar depression; BPD: borderline personality; MDQ: Mood Disorder Questionnaire; MSI: McLean Screening Instrument. 
Table 2

Results MDQ and MSI questionnaires in patients $(n=313)$.

\begin{tabular}{|c|c|c|c|c|c|c|}
\hline & BD-I & BD-II & BD unspecified & UD & Others & $P^{*}$ \\
\hline MDQ mean & $10.4 \pm 2.9$ & $9.9 \pm 3.3$ & $10 \pm 2.7$ & $4.9 \pm 3.7$ & $4.9 \pm 4.4$ & $<0.0001$ \\
\hline MSI mean & $5.1 \pm 2.6$ & $6.3 \pm 2.3$ & $7.6 \pm 2.7$ & $5.5 \pm 2.7$ & $5.2 \pm 2.5$ & 0.030 \\
\hline MDQ positive, $n(\%)$ & $27(75)$ & $34(62)$ & $7(88)$ & $34(19)$ & $7(23)$ & $<0.0001$ \\
\hline MDQ negative, $n(\%)$ & $9(25)$ & $21(38)$ & $1(12)$ & $149(81)$ & $24(77)$ & $<0.0001$ \\
\hline MSI positive, $n(\%)$ & $12(31)$ & 27 (49) & $6(75)$ & $74(39)$ & $9(5)$ & 0.090 \\
\hline MSI negative, $n(\%)$ & $24(69)$ & $28(51)$ & $2(25)$ & $109(61)$ & $22(95)$ & 0.090 \\
\hline
\end{tabular}

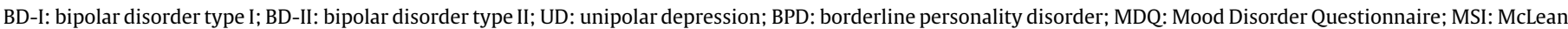
Screening Instrument.

$P$-values reflect differences between group of patients with bipolar disorder (I; II- or unspecified type) with groups of patients with unipolar depression and others.

response. The second part of the questionnaire inquires whether several of these symptoms have been experienced during the same time period, and the third part asks about the severity of the resulting problems. The screening is regarded as positive when seven or more symptoms have occurred within the same episode, causing moderate to severe problems. In the correlation analysis only the first question's responses were used; Cronbach's alpha for them was 0.89 , indicating excellent internal consistency.

\subsection{McLean Screening Instrument (MSI)}

The MSI is a ten-item questionnaire designed to screen for BPD [36]; it has been translated into Finnish [19]. Each item requires a "yes/no" response. Each positive item indicates the presence of BPD symptoms. Previous research has suggested that a useful clinical cut-off score in predicting BPD among adults is seven or more. Cronbach's alpha for MSI was 0.747 , indicating a good internal consistency.

\subsection{Statistical analysis}

Analyses were performed using the Mplus 7.1 software [21]. Because the items were categorical, the WLSMV estimator was used to estimate the models, and the model is effectively an item-response theory (IRT) model with two factors (MDQ and MSI). Potential cross-loadings were examined by looking at model Modification Indexes, which are used to identify structural misspecifications in the model. The correlation from 0.8 to 1 was considered as "very strong", from 0.6 to 0.79 as "strong", from $0.40-0.59$ as "moderate", from $0.20-0.39$ as "weak" and less than 0.2 as "very weak" [8].

\section{Results}

\subsection{MDQ and MSI scores}

The BD patients scored significantly higher on the MDQ and fell more often into MDQ positive category than their UD and "others" counterparts (see Table 2).

\subsection{Correlation analysis}

A moderate statistically significant correlation $(r=0.431$, $P<0.001$ ) was found between the MDQ and MSI total scores. Item-by-item correlations are shown in Table 3. More specifically, the MSI items of "impulsivity" and "mood instability" correlated significantly and coherently with all MDQ items, with $r$ coefficients ranging from 0.263 to 0.397 .

\subsection{Factor analysis}

In the two-factor IRT model, all MDQ and MSI items predictably loaded on their respective factors (all $P<0.01$ ), Based on Modification Indexes, two MSI items had significant cross-loadings on the MDQ factor (both $P<0.01$ ): "impulsivity" and "mood instability." Three MDQ items in turn had significant crossloadings with the MSI factor (all $P<0.01$ ): "irritability", "flight of thoughts", and "distractibility" (Fig. 1).

\subsection{Correlation analysis in diagnostic subgroups}

The correlation between the MDQ and MSI emerged independently of the diagnosis and more prominently for patients with

Table 3

Item-by-item correlations between the MDQ and MSI in patients $(n=313)$.

\begin{tabular}{|c|c|c|c|c|c|c|c|c|c|c|}
\hline \multirow[t]{2}{*}{ MDQ } & \multicolumn{10}{|l|}{ MSI } \\
\hline & $\begin{array}{l}\text { Troubled } \\
\text { relationships }\end{array}$ & $\begin{array}{l}\text { Suicidal } \\
\text { behaviour }\end{array}$ & Impulsivity & $\begin{array}{l}\text { Mood } \\
\text { instability }\end{array}$ & $\begin{array}{l}\text { Increased } \\
\text { anger }\end{array}$ & Distrustfulness & $\begin{array}{l}\text { Dissociative } \\
\text { symptoms }\end{array}$ & Emptiness & $\begin{array}{l}\text { Identity } \\
\text { disturbance }\end{array}$ & $\begin{array}{l}\text { Fear of } \\
\text { abandonment }\end{array}$ \\
\hline Elevated mood & 0.105 & 0.100 & $0.304^{* *}$ & $0.381^{* *}$ & 0.107 & $0.154^{* *}$ & $0.178^{* *}$ & $0.140^{*}$ & 0.100 & 0.069 \\
\hline Irritability & $0.281^{* *}$ & $0.134^{*}$ & $0.277^{* *}$ & $0.263^{* *}$ & $0.237^{* *}$ & $0.187^{* *}$ & 0.066 & -0.007 & 0.040 & $0.132^{*}$ \\
\hline Increased self-confidence & 0.041 & 0.082 & $0.310^{* *}$ & $0.328^{* *}$ & 0.079 & $0.139^{*}$ & 0.089 & $0.145^{* * *}$ & 0.066 & $0.118^{*}$ \\
\hline Decreased need for sleep & 0.059 & $0.172^{* *}$ & $0.254^{* *}$ & $0.351^{* *}$ & 0.101 & $0.169^{* *}$ & $0.206^{* *}$ & $0.148^{* *}$ & 0.058 & 0.088 \\
\hline Talkativeness & 0.050 & 0.043 & $0.256^{* *}$ & $0.277^{* *}$ & $0.127^{*}$ & $0.154^{*}$ & $0.146^{* *}$ & 0.110 & $0.166^{* *}$ & $0.140^{*}$ \\
\hline Flight of thoughts & 0.018 & 0.047 & $0.276^{* *}$ & $0.376^{* *}$ & $0.121^{*}$ & $0.142^{*}$ & $0.186^{* *}$ & $0.163^{* *}$ & $0.135^{*}$ & 0.026 \\
\hline Distractibility & 0.023 & 0.083 & $0.175^{* *}$ & $0.301^{* *}$ & $0.178^{* *}$ & $0.212^{* *}$ & $0.310^{* *}$ & $0.194^{* *}$ & $0.188^{* *}$ & 0.087 \\
\hline Increased energy & $0.124^{*}$ & $0.149^{* *}$ & $0.358^{* *}$ & $0.311^{* *}$ & $0.154^{* *}$ & $0.112^{*}$ & $0.167^{* *}$ & 0.087 & 0.080 & $0.128^{*}$ \\
\hline Increased activity & 0.092 & $0.118^{*}$ & $0.310^{* *}$ & $0.311^{* *}$ & $0.123^{*}$ & $0.115^{*}$ & $0.142^{*}$ & 0.082 & 0.065 & 0.096 \\
\hline Increased sociality & 0.026 & 0.058 & $0.229^{* * *}$ & $0.307^{* *}$ & 0.074 & $0.132^{*}$ & $0.153^{*}$ & $0.171^{* *}$ & 0.104 & 0.088 \\
\hline Increased sexuality & 0.080 & $0.112^{*}$ & $0.296^{* *}$ & $0.327^{* *}$ & $0.176^{* *}$ & 0.078 & 0.085 & $0.133^{* *}$ & $0.125^{*}$ & 0.044 \\
\hline High risk behaviour & 0.110 & $0.176^{* *}$ & $0.260^{* *}$ & $0.397^{* *}$ & 0.109 & $0.121^{*}$ & $0.193^{* *}$ & $0.120^{*}$ & 0.105 & 0.070 \\
\hline Money spending & $0.188^{* * *}$ & $0.141^{*}$ & $0.371^{* *}$ & $0.339^{* *}$ & $0.158^{* *}$ & $0.140^{*}$ & $0.227^{* * *}$ & $0.116^{*}$ & 0.081 & 0.040 \\
\hline
\end{tabular}

MDQ: Mood Disorder Questionnaire; MSI: McLean Screening Instrument.

${ }^{*} P<0.05$.

** $P<0.005$. 


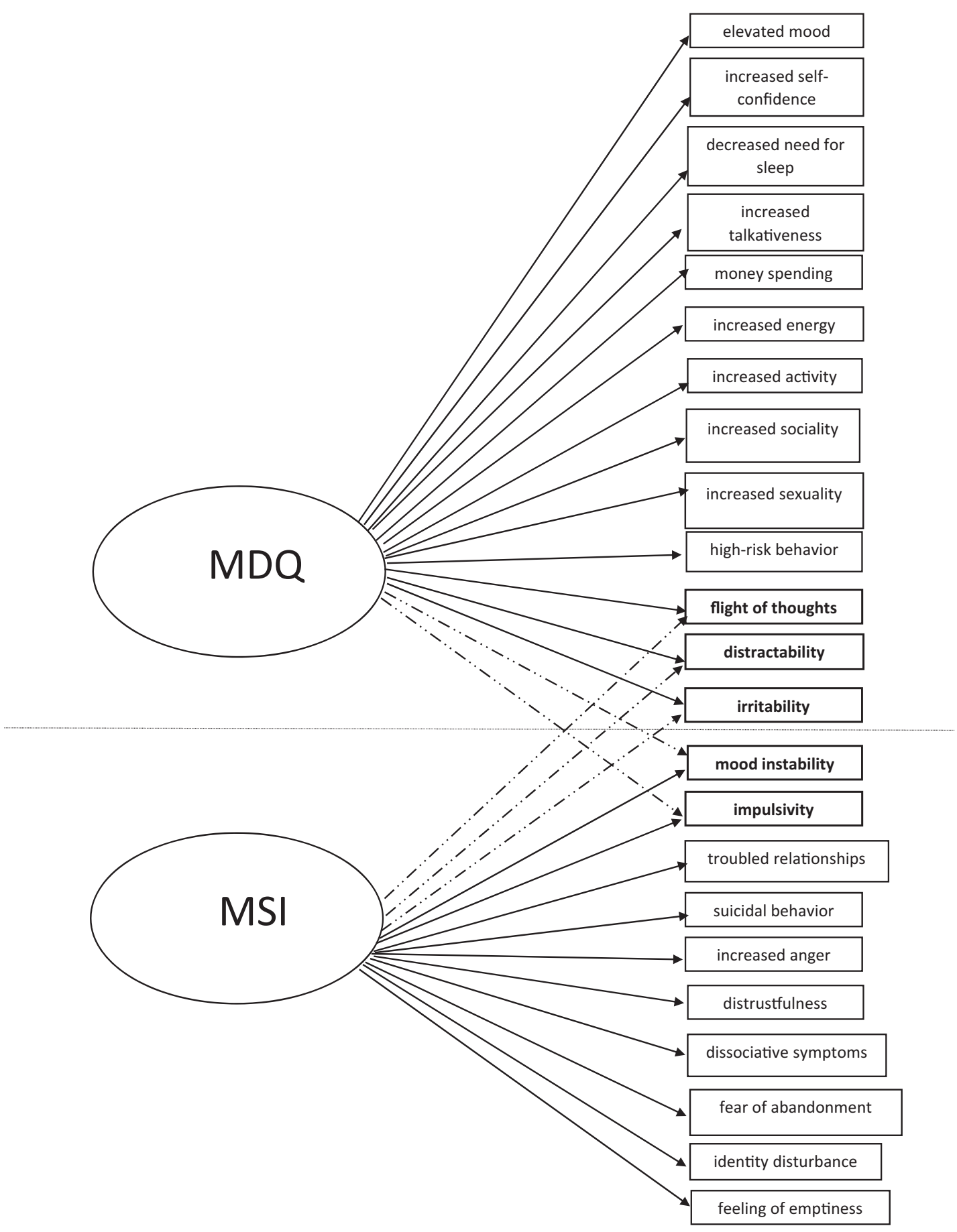

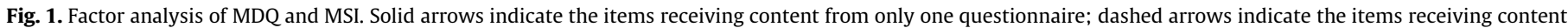
from both questionnaires. MDQ: Mood Disorder Questionnaire; MSI: McLean Screening Instrument.

BPD and BD than for others. $r$ values between total scores of MSI and MDQ and details of item-by-item analysis are shown in Table 4.

\section{Discussion}

We found a moderate correlation between total scores of selfreported symptoms of bipolar disorder (BD) on the Mood Disorder Questionnaire (MDQ) and borderline personality disorder (BPD) on the McLean Screening Instrument (MSI) among patients with mood disorders treated in psychiatric specialized units. In the item-by-item analysis, the most consistent correlation emerged between the MSI items of "mood instability" and "impulsivity" and all MDQ items. In the factor analysis, the items of "flight of thoughts", "distractibility" and "irritability" appeared to overlap.

To our knowledge, this is the first study on the phenomenological overlap between BP and BPD based on the self-report screening instruments MSI and MDQ. Strengths of our study included the relatively large number of patients and the representativeness of mood disorder patients recruited from specialized psychiatric care. However, there were also several limitations. First, the response 
Table 4

Correlation analysis between the MDQ and MSI within diagnostic subgroups.

\begin{tabular}{|c|c|c|c|}
\hline Subgroup & $n$ & $\begin{array}{l}r \text { between total } \\
\text { scores of MDQ } \\
\text { and MSI }\end{array}$ & Main findings from item-by-item analysis. Correlations were ${ }^{* *}$ as listed below \\
\hline All patients with BP and BPD & 147 & $0.274^{*}$ & $\begin{array}{l}\text { Moderate between MSI "mood instability" and all MDQ items; weak between } \\
\text { MSI "impulsivity" and "irritability" and "money spending" }\end{array}$ \\
\hline BD with comorbid BPD & 17 & $0.410^{*}$ & $\begin{array}{l}\text { Strong between MSI "mood instability" and MDQ "elevated mood", } \\
\text { "irritability"; moderate between MSI "impulsivity" and MDQ "money } \\
\text { spending", "interpersonal disputes", "irritability" }\end{array}$ \\
\hline All patients with BD & 99 & $0.349^{*}$ & Weak between MSI "mood instability" and all MDQ items \\
\hline BD-I & 36 & $0.296^{*}$ & $\begin{array}{l}\text { Moderate between MDQ "irritability" and MSI "interpersonal disputes", } \\
\text { "increased anger". Moderate between MSI "mood instability" and MDQ } \\
\text { "decreased need for sleep", "flight of thoughts", "increased activity", etc. }\end{array}$ \\
\hline BD-II & 55 & $0.475^{*}$ & $\begin{array}{l}\text { Moderate between MSI "mood instability" and all MDQ items. Moderate } \\
\text { between MSI "impulsivity" and "decreased need for sleep", "increased energy", } \\
\text { "talkativeness", "increased self-confidence" }\end{array}$ \\
\hline BD without comorbid BPD & 82 & $0.355^{*}$ & Weak or moderate between MSI "mood instability" and all MDQ items \\
\hline UD and comorbid BPD & 39 & $0.328^{*}$ & $\begin{array}{l}\text { Weak between MSI "impulsivity" and MDQ "increased self-confidence", } \\
\text { "talkativeness", "increased energy", etc. Moderate between MSI "mood } \\
\text { instability" and MDQ "irritability" }\end{array}$ \\
\hline UD without BPD & 144 & $0.502^{*}$ & Weak between MSI "impulsivity" "mood instability" and all MDQ items \\
\hline BPD & 65 & $0.404^{*}$ & $\begin{array}{l}\text { Moderate between MSI "mood instability"; "impulsivity" and MDQ } \\
\text { "irritability", "increased energy", "increased activity" }\end{array}$ \\
\hline Excluding group "others" & 283 & $0.429^{*}$ & $\begin{array}{l}\text { Weak or moderate between MSI "mood instability", "impulsivity" and all MDQ } \\
\text { items }\end{array}$ \\
\hline
\end{tabular}

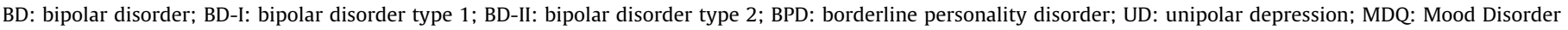
Questionnaire; MSI: McLean Screening Instrument.

${ }^{*} P<0.005$.

$r$ value not shown.

rate was $35 \%$, likely due to the survey being conducted within routine service facilities. Nevertheless, the analysis of representativeness indicated no significant differences in terms of age or sex between our cohort and the whole population of patients treated in the years 2011 and 2012. Second, the clinical diagnoses were not verified with structured clinical diagnostic interview instruments. However, all patients had been diagnosed with mood disorders in psychiatric settings specialized in their treatment, and all available relevant diagnostic information on each patient was re-evaluated by the authors. Moreover, the focus of this study was in responses to screens, not diagnoses per se.

Problematic boundaries between BD and BPD as well as difficulties in their differential diagnostics have been topics of numerous discussions for a long time $[1,16,23,24,37]$. The moderate correlation between the total scores of the screening instruments MDQ and MSI indicates partial similarity in selfreported features of BD and BPD. In the item-by-item analysis, the MSI items of "mood instability" and "impulsivity" correlated consistently with all MDQ items. Furthermore, for patients with both BPD and BD, particularly BD type II, the correlation was shown to be stronger than for other groups.

Mood instability and impulsivity are core features of BPD, but both can also be observed in patients with BD [3,5,9,22,27]. Some experts have postulated cyclothymic affective temperament to underlie disorders of emotional regulation in both BPD and BD $[25,28]$. Nevertheless, some distinctions in the nature of "affective instability" and "impulsivity" in BD and BPD have been described $[4,9,10,14,15,22]$. Our study indicates that the symptomatic overlap between BD and BPD in "impulsivity" and "mood instability" is also revealed in self-reports. Consequently, patients with self-reported "impulsivity" and "mood instability" may score higher on the MDQ even in the absence of bipolarity. On the other hand, patients with a history of hypomania may score higher on the MSI, leading to false interpretation of BPD.

Factor analysis revealed significant cross-loadings with five items (see Fig. 1). As a result, a patient scoring high on the MSI may also score high on the MDQ, probably due to difficulties in distinguishing from the hypomania items of "irritability", "flight of thoughts" and "distractibility". Correspondingly, patients scoring high on the MDQ may have increased MSI scores due to misinterpretation of the MSI items of "mood instability" and "impulsivity". Thus, MSI and MDQ scores associate with each other due to these symptoms, which may easily lead into erroneous diagnostic conclusions, unless both aspects of psychopathology are carefully evaluated.

The use of these screening instruments is based on the patient's own estimation of the presence or absence of symptoms. Several factors may influence patients' ability to answer to the scales questions, including well described impairments in social cognition [20,26,30], autobiographical memory disruptions $[7,33]$ and current mood, among others. Our results indicate an overlap in the self-reported features of "flight of thoughts", "distractibility" and "irritability" on the MDQ and "mood instability" and "impulsivity" on the MSI. Despite this overlap, the majority of the other items on both questionnaires involve specific features of each disorder, which can help to distinguish between them.

Both the MDQ and MSI were created to improve recognition of a specific disorder. When interpreting the results of screening it is likely useful to evaluate how patient's answers are distributed between overlapping and non-overlapping items of the MDQ and MSI. Even more important clinically is not to limit evaluation only on one specific diagnostic tool, but to consider alternative explanations for apparent psychopathology, and to conduct careful, comprehensive clinical interviews to differentiate between $\mathrm{BPD}$ and $\mathrm{BD}$, or to ascertain their concurrent presence.

\section{Conclusions}

The MDQ and MSI measure partly the same dimensions in patients with mood disorders. The self-reported symptoms of "affective instability", "impulsivity", "irritability", "flight of thoughts" and "distractibility" are shared and may lead to misinterpretations of 
screenings. However, non-overlapping items on both questionnaires are more specific to the disorders for which they are designed, and thus, could be given more weight in differential diagnosis.

\section{Disclosure of interest}

The authors declare that they have no conflicts of interest concerning this article.

\section{References}

[1] Akiskal HS. Demystifying borderline personality: critique of the concept and unorthodox reflections on its natural kinship with the bipolar spectrum. Acta Psychiatr Scand 2004;110(6):401-7.

[2] American Psychiatric Association. Diagnostic and statistical manual of mental disorders, Fourth edition, DC: Washington; 1994

[3] Antoniadis D, Samakouri M, Livaditis M. The association of bipolar spectrum disorders and borderline personality disorder. Psychiatr Q 2012;83(4): 449-65

[4] Boen E, Hummelen B, Elvsashagen T, Boye B, Andersson S, Karterud S, et al. Different impulsivity profiles in borderline personality disorder and bipolar Il disorder. J Affect Disord 2015;170:104-11.

[5] Coulston CM, Tanious M, Mulder RT, Porter RJ, Malhi GS. Bordering on bipolar: the overlap between borderline personality and bipolarity. Aust N Z J Psychiatry 2012;46(6):506-21.

[6] Das P, Calhoun V, Malhi GS. Bipolar and borderline patients display differential patterns of functional connectivity among resting state networks. Neuroimage 2014;98:73-81.

[7] Dere E, Pause BM, Pietrowsky R. Emotion and episodic memory in neuropsychiatric disorders. Behav Brain Res 2010;215(2):162-71.

[8] Evans JSBT, Over DE. Rationality and reasoning. Hove, England: Psychology press; 1996.

[9] Henry C, Mitropoulou V, New AS, Koenigsberg HW, Silverman J, Siever LJ. Affective instability and impulsivity in borderline personality and bipolar II disorders: similarities and differences. J Psychiatr Res 2001;35(6):307-12.

[10] Henry C, Van den Bulke D, Bellivier F, Roy I, Swendsen J, M'Bailara K, et al. Affective lability and affect intensity as core dimensions of bipolar disorders during euthymic period. Psychiatry Res 2008;159(1-2):1-6.

[11] Hirschfeld RM. Bipolar spectrum disorder: improving its recognition and diagnosis. J Clin Psychiatry 2001;62(Suppl. 14):5-9.

[12] Hirschfeld RMA, Williams JBW, Spitzer RL, Calabrese JR, Flynn L, Keck PEJ, et al. Development and validation of a screening instrument for bipolar spectrum disorder: the mood disorder questionnaire. Am J Psychiatry 2000;157(11): 1873-5.

[13] Isometsa E, Suominen K, Mantere O, Valtonen H, Leppamaki S, Pippingskold M, et al. The mood disorder questionnaire improves recognition of bipolar disorder in psychiatric care. BMC Psychiatry 2003;3:8.

[14] Koenigsberg HW. Affective instability: toward an integration of neuroscience and psychological perspectives. J Pers Disord 2010;24(1):60-82.

[15] Lijffijt M, Lane SD, Moeller FG, Steinberg JL, Swann AC. Trait impulsivity and increased pre-attentional sensitivity to intense stimuli in bipolar disorder and controls. J Psychiatr Res 2014;60C:73-80.

[16] Mackinnon DF, Pies R. Affective instability as rapid cycling: theoretical and clinical implications for borderline personality and bipolar spectrum disorders. Bipolar Disord 2006;8(1):1-14.

[17] Mantere O, Suominen K, Leppamaki S, Valtonen H, Arvilommi P, Isometsa E. The clinical characteristics of DSM-IV bipolar I and II disorders: baseline findings from the jorvi bipolar study (JoBS). Bipolar Disord 2004;6(5):395-405.
[18] Mazza M, Di Nicola M, Janiri L, Bria P. To be or not to be a bipolar disorder patient: problems with diagnosis. J Nerv Ment Dis 2013;201(5):435-7.

[19] Melartin T, Hakkinen M, Koivisto M, Suominen K, Isometsa ET. Screening of psychiatric outpatients for borderline personality disorder with the McLean screening instrument for borderline personality disorder (MSI-BPD). Nord J Psychiatry 2009;63(6):475-9.

[20] Mier D, Lis S, Esslinger C, Sauer C, Hagenhoff M, Ulferts J, et al. Neuronal correlates of social cognition in borderline personality disorder. Soc Cogn Affect Neurosci 2013;8(5):531-7.

[21] Muthén LK, Muthén BO. Mplus user's guide, Sixth edition, Los Angeles: CA: Muthén \& Muthén; 2010.

[22] Nica EI, Links PS. Affective instability in borderline personality disorder: experience sampling findings. Curr Psychiatry Rep 2009;11(1):74-81.

[23] Paris J. Borderline or bipolar? Distinguishing borderline personality disorder from bipolar spectrum disorders. Harv Rev Psychiatry 2004;12(3):140-5.

[24] Paris J, Black DW. Borderline personality disorder and bipolar disorder: what is the difference and why does it matter? J Nerv Ment Dis 2015;203(1): $3-7$.

[25] Perugi G, Akiskal HS, Lattanzi L, Cecconi D, Mastrocinque C, Patronelli A, et al. The high prevalence of "soft" bipolar (II) features in atypical depression. Compr Psychiatry 1998;39(2):63-71.

[26] Preissler S, Dziobek I, Ritter K, Heekeren HR, Roepke S. Social cognition in borderline personality disorder: evidence for disturbed recognition of the emotions, thoughts, and intentions of others. Front Behav Neurosci 2010;4:182.

[27] Renaud SM, Zacchia C. Toward a definition of affective instability. Harv Rev Psychiatry 2012;20(6):298-308.

[28] Rihmer Z, Akiskal KK, Rihmer A, Akiskal HS. Current research on affective temperaments. Curr Opin Psychiatry 2010;23(1):12-8.

[29] Rush JA. Preface. In: Rush JA, First MB, Blacker D, editors. Handbook of Psychiatric Measures. Second edition, American Psychiatric Association; 2008

[30] Samame C, Martino DJ, Strejilevich SA. An individual task meta-analysis of social cognition in euthymic bipolar disorders. J Affect Disord 2015;173: 146-53.

[31] Stone MH. The brain in overdrive: a new look at borderline and related disorders. Curr Psychiatry Rep 2013;15(10):399 [013-0399-7].

[32] Stone MH. A new look at borderline personality disorder and related disorders: hyper-reactivity in the limbic system and lower centers. Psychodyn Psychiatry 2013;41(3):437-66.

[33] Winter D, Elzinga B, Schmahl C. Emotions and memory in borderline personality disorder. Psychopathology 2014;47(2):71-85.

[34] Witt SH, Kleindienst N, Frank J, Treutlein J, Muhleisen T, Degenhardt F, et al. Analysis of genome-wide significant bipolar disorder genes in borderline personality disorder. Psychiatr Genet 2014;24(6):262-5.

[35] World Health Organization. International classification of disease, 10th ed., Geneva; 1992.

[36] Zanarini MC, Vujanovic AA, Parachini EA, Boulanger JL, Frankenburg FR, Hennen J. A screening measure for BPD: the McLean screening instrument for borderline personality disorder (MSI-BPD). J Pers Disord 2003;17(6): 568-73.

[37] Zimmerman M, Morgan TA. Problematic boundaries in the diagnosis of bipolar disorder: the interface with borderline personality disorder. Curr Psychiatry Rep 2013;15(12):422 [013-0422-z].

[38] Zimmerman M, Ruggero CJ, Chelminski I, Young D. Is bipolar disorder overdiagnosed? J Clin Psychiatry 2008;69(6):935-40.

[39] Zimmerman M, Galione JN, Ruggero CJ, Chelminski I, Dalrymple K, Young D. Overdiagnosis of bipolar disorder and disability payments. J Nerv Ment Dis 2010;198(6):452-4.

[40] Zimmerman M, Ruggero CJ, Chelminski I, Young D. Psychiatric diagnoses in patients previously overdiagnosed with bipolar disorder. J Clin Psychiatry 2010;71(1):26-31. 